\title{
Amelioration of tailings into a blended waste cap for tailings closure
}

\author{
GOLAM TAKI $^{1 *}$, TALITHA SANTINI ${ }^{1}$ \\ ${ }^{1}$ School of Agriculture and Environment, The University of \\ Western Australia, 35 Stirling Highway, 6009 WA, \\ Australia \\ (*correspondence: golam.taki@research.uwa.edu.au)
}

Establishment of a sustainable vegetation cover on tailings dams is fundamental to sustainable environmental management within the mining industry for controlling erosion and building an environmentally acceptable landscape following cessation of operations. Vegetating bauxite residue poses particular challenges due to the highly saline-sodic tailings material and elevated concentrations of As, V, Cr, Co, and Ni (100 - 1000 ppm). In this study, a sustainable tailings closure strategy is presented for bauxite residue, in combination with various amendments (fly ash, eucalyptus mulch, sewage sludge, and waste acid), to create a 'Blended Waste Cap' for supporting revegetation.

The results from a glasshouse leaching experiment are presented using bauxite residue blended with four other waste products available on site: vegetation mulch $(0,5,10 \mathrm{wt} . \%)$, fly ash $(0,10,20$ wt. $\%)$, sewage sludge $(0,5,10$ wt. \%), and hydrochloric acid $(0,5,10 \mathrm{wt} . \%)$, to investigate the efficacy of the amendments to reduce the alkalinity, sequester trace elements, and increase plant-available nutrients. Results of ICP-OES analyses of solids and leachates to examine element and nutrient cycling, and synchrotron $\mathrm{X}$-ray diffraction to quantify mineral concentrations and characterise the structural properties of resident mineralogical phases in the solids are presented. This study provides new insights into trace element geochemistry and mineralogy at alkaline $\mathrm{pH}$, particularly in response to specific amendment applications. This study also contributes to understanding the natural caron sequestration of bauxite residue, improving the accuracy of predictive geochemical models and enabling potential ecotoxicological or biomagnification risks associated with tailings facility closure and revegetation to be identified early. 